\title{
Schooling, Income and Social Position in Different Countries
}

\author{
Odaci Luiz Coradini \\ Institute of Philosophy and Human Sciences, Federal University of Rio Grande do Sul, Porto Alegre, Brazil
}

\author{
Email address: \\ coradini@ufrgs.br
}

\section{To cite this article:}

Odaci Luiz Coradini. Schooling, Income and Social Position in Different Countries. International Journal of Science, Technology and Society. Vol. 7, No. 6, 2019, pp. 78-86. doi: 10.11648/j.ijsts.20190706.11

Received: July 17, 2019; Accepted: August 16, 2019; Published: November 25, 2019

\begin{abstract}
This article consists of the exposition of part of the research results focused on the examination of the relations between economic valorization of formal education and social position. The objective of this research is to take the set of social position indicators with information available in official statistics with compatible variables between different countries. Besides the compatibility of the pertinent variables, another inclusion criterion is the existence of information available in continuous values for the amount of income and the number of years of study. Based on this, a set of 13 countries were included (under central and peripheral conditions). Differences in the economic valuation of the amount of education are measured particularly by comparing the average income and years of education for each category of variables under consideration. Of the set of indicators retained with information available from sources, a first block refers more directly to variables linked to occupational categories, status in employment and educational level, in addition to the amount of income. A second block of indicators is more directly linked to the position in center/periphery relations and the conditions of social integration. Finally, a third block of indicators focuses on what is generally considered as social capital. In the present article, due to the lack of space for the total results to be exposed, the focus is on the first set of indicators, relative amount of income, occupational categories, status in employment and educational level Despite the impossibility of exposing the totality of the results in a single article, regarding the included indicators, they are very strong and systematic. The "plus" in valuing formal education is extremely differentiated, with the respective positions of the always analogous or similar categories. This covers either occupational categories or groupings or status in employment and educational attainment. Despite the inclusion of countries in central and peripheral conditions and differences in outcomes, the relative positions of the categories with the highest "plus" in.
\end{abstract}

Keywords: Returns of Education, Differentiated Value of Education, Social Position, Occupational Categories, Scholarly Titles, Center/Periphery Relations

\section{Introduction}

This paper perceives the differentiated conditions of value of formal education as a sociological issue. From a specific approach: this differentiated value of formal education is namely seen as a result of the confrontation between resources and principles of social hierarchy. Thus, there is no consideration for the supposed "value" of education, either as a "return" of money investment, or as more general "social" effects.

The issue involves different theoretical and conceptual approaches-such as those linked to credentialism and its confrontation with the human capital theory-, conceptual and methodological discussions about social capital, among others. However, it also covers sociological problems that touches different theoretical perspectives, which consist of the relations between what is socially objectified and what is implicit in social practices and hierarchies [3, 5]. Thus, in addition to the theoretical approaches involved in this proposition such as those of credentialism ${ }^{1}$-to the study of conceptual problems and the effects of social capital in its different and contradictory versions [8, 14, 15, 13]-there are also other major analytical problems. These are, for example, the relations between conceptual definitions of social

1 See especially [9] and [7]. For a balance of these confrontations, see [2]. 
sciences with the means and instruments of access to the empirical categories, and to the principles of social hierarchy, and their codification. This paper also deals with the problems involved in social hierarchy, its codification and classification schemes, particularly with regards to those of official statistics.

The socially objectified character of formal education refers especially to the correspondence between certain levels or amounts of schooling in reference to respective degrees. This title, as in the case of other types of titles, is officially sanctioned, regulated, and guaranteed [3]. However, apart from this objectivation as a title, which makes it "universal", therefore, transcendent to its eventual bearer, this character of formal education as socially objectified occurs in the value given to it in certain markets, particularly in work and scholarly markets. It should be also noted that it is this relationship between the value given to education and the markets that underlies the controversies about its actual value. In summary, it is the issue of apprehension and discernment of what is being valued or what serves as the basis for the value of scholarly titles. The theoretical perspectives more directly based on objectivist approaches, among which (particularly by economists who follow human capital theories) take the supposedly acquired "competency" that would have positive effects on labor productivity as an explanatory principle for the value given to school titles. In the opposite pole are those who adhere to the credential value of the degree, which refers to value criteria that are not necessarily "technical" or intrinsic to strict school training [2, 5-7, 9, 16].

Even without going into the intricacies of these confrontations, it is important to point out that even a good part of those who adhere to a certain economicism, which perceives the social structure as a projection of the homo economicus, in addition to strictly economic market relations, included something that is usually referred as the "social". Therefore, despite of how unidimensional the perspectives based on the homo economicus is, the "social", conceived as following the same logic of action and rationality as those of the economic market, is not reducible to this. This is the case of the very basic formulations of the human capital theory by the original economists who formulated it (G. Becker, Minceur), and particularly of sociologists who follow this type of perspective and other approaches derived from neoclassical economics, such as rational choice theory. The most common definition of the "social" in these perspectives (based on homo economicus) is social capital. Despite the controversies of the conceptual definitions and inclusion criteria of what would comprise this social capital, there is a common basis that takes it as a derivative and component of a set of other types of capital, such as physical, financial, and human capital. This human capital is directly associated with schooling and knowledge, yet for this paper, it is important to highlight that it is conceived as directly boosting economic capital. The same is true of what is considered social capital, which in its original formulation by the study [8] is directly linked to family relations and civic engagement, and has a boosting effect for other types of capital, particularly human capital. Despite the variation between different versions of these perspectives as the basis of human capital, whether [8], the so-called social resources theory [13], or the one by the study [14], this "social", usually defined as social capital, is directly associated with the engagement in civic organizations and has positive effect on other forms of capital, particularly economic and institutions which are regarded as "democratic" or pluralistic. Since the countries of central capitalism would have more intense civic organizations and civic engagement, it is supposed that this would have positive effects on the value given to formal education, either in strictly economic terms or in more "social" terms (for more details, see especially.

In this context, it is important to highlight that the effort to compare different countries-central and periphery regions in particular-is to confront these hypotheses regarding the effects of social capital in the value given to formal education. In this way, after having examined the relations of the differentiated value of formal education with only one country, this article aims is an effort to simultaneously confront this differentiated value with the social position indicators of each of the 13 countries included in the study and compares these countries with each other. In this comparison, the confrontation between those in central and periphery is particularly interesting. This follows from the basic hypothesis that, on the one hand, the advantages of the value of formal education are directly linked to social position and capital. On the other hand, however, they are also directly associated with periphery conditions. Thus, based on the theoretical perspective and adopted definition of social capital $[4,6]$ although central countries may present higher rates of participation in organizations and civic activities-it is the periphery countries in particular that have the greatest advantage giving differentiated valuation of formal education.

\section{Method}

In terms of sources of empirical material, the study first consulted the census data for a set of 13 countries which were provided by the IPUMs International [12]. These countries divulged information on the amount of income and years of education in continuous values, covering central and periphery countries. For some countries, these census data were complemented by other official statistical sources, particularly household surveys (especially those whose complements include relevant information, such as those related to trade unions or associative memberships [11], among others. The World Value Survey (WVS) [18] archives were also used, particularly regarding indicators of what is generally considered as social capital from the perspectives of civic morality [8, 14].

Regarding the set of retained indicators, it should be noted that, as already mentioned, the differentiated value of formal education is seen as a result of the confrontation between 
resources and principles of social hierarchy. As a general working hypothesis, these resources and principles of social hierarchy are three interdependent modalities, directly associated with the multidimensionality of the social structure. The first modality is more directly associated with those resources most commonly regarded as constituents of the structure of social positions, particularly economic capital and what is generally included as cultural capital in its many variations [6]. This types of resources tend to be more socially explicit, even in the schemes of statistical classification. A second type of resources associated and interdependent with the former is more directly related to the conditions of insertion and social integration. Although the available sources mention some indicators that are more directly associated with the first type mentioned above and others that can be considered as directed particularly to this type of resource-which in turn consists of the conditions and possibilities for social insertion and integration-it should be emphasized that these differences are not exclusionary criteria, since, at least hypothetically, these are different dimensions of the social structure. It is the case, for example, occupational classifications are more directly associated with the first type of resource. However, these same categories can be taken as directly associated with the conditions for social insertion and integration. This second type of resource has a lower degree of social visibility and statistical codification, and as a resource, it tends to appear in an indirect manner. In the available sources, these are particularly those indicators considered as "non-economic", such as cleavages and divisions due to ethnicity, religion, place of birth and residence, gender, and so on. In addition to the lower degree of social visibility and codification and statistical systematization, this type of resource may be more directly associated with a lower degree of social categorization and institutionalization. As a result, their significance as a resource for social hierarchy tends to be associated with some form of reconversion of expressed purpose and function. In general, these are the criteria of inclusion in what is considered as social capital by theoretical positions based on civic morality and the perspective of the homo economicus $[8,13,14]$.

Lastly, in an interdependent manner, a third type of resource in the social hierarchy consists of the position in center/periphery relations. Despite the difficulties of social sciences to obtain a definitive definition of this type of relation [1], at least as a general hypothesis, it seems evident that it consists of one of the basic determinants of social hierarchies and, also, value given to formal education. However, with regards to the differentiated value of formal education, the evidence goes exactly on the opposite direction of what is supported by literature related to social capital based on civic morality. According to this literature, in any of its versions, social capital would have positive effects on the value of schooling. Of course, central countries would represent the positive pole, where social capital, in the sense of moral or civic engagement, would be stronger. However, obtained results systematically show that the greatest gains or "plus" in value given to formal education occur in periphery countries, particularly for certain social categories of this pole. Yet, the intensity of the association between position in center/periphery relations and value of formal education is not restricted to the comparison between countries, also covering the socio-geographical units and the migrations within each country.

The countries included in the more detailed examination are those whose censuses count the amount of income and the amount of formal education in continuous values. In the case of the amount of formal education, this occurs when this information is in the years of study and not in intervals or degrees or other categorizations. Under the current condition of the sources, a total of 13 countries met the criteria: the United States (US), Canada, Mexico, Brazil, South Africa (SA), India, Indonesia, Colombia, Jamaica, Puerto Rico, the Dominican Republic, Venezuela, and Uruguay. However, since not all censuses of these countries have the complete information for these conditions, the dates of the censuses selected for detailed analysis are somewhat varied, however, there wereare no significant differences between the censuses of the different dates.

Considering that the research problem focuses on the differentiated value of formal education, after testing different exploratory techniques, the most important one is the assessment of the advantages or disadvantages of this differentiated value according to the indicators of social position and social capital. To do so, the most commonly used measurement technique, although relatively simple, was the comparison of averages. Since both the amount of income and the number of years of study are available as continuous values in the censuses of the countries included, this made it possible to obtain the respective averages of income and years of study for each census and respective categories of variables related to social position and social capital. This way, it is possible to compare the averages of each variable category related to social position and social capital to the set of the respective universe. At the same time, it is possible to discern those categories whose average income or years of study are higher or lower than the total universe and, more importantly, the differences in their respective positions, positive or negative, in each of these income averages or years of study. In short, it is possible to obtain the position regarding the amount of income or of formal education and the plus" or degree of advantage or disadvantage in the value of formal education. Of course, in relation to complementary sources, such as the WVS archives, the techniques used are different and more conventional, since in this case it is not possible to link the variables related to social engagement or capital with the "plus" in the value of formal education, for the information is not available for this purpose.

Regarding the three axes of analysis mentioned, that is, the relations of the value given to formal education against social position indicators, the position in the center/periphery relations and social capital, this article only presents the results for the first one, for including the whole set would make the text too long. This, the rest will be presented in another article. 


\section{Result: Occupational Categories and Differences in the Value of Formal Education}

Occupational categories are present in the censuses in different ways and, for the purpose of this study, they are considered in a more aggregated and detailed version, besides the position in the occupation (class of worker). The more aggregated version, with around 10 groupings, has the advantage of being more compatible, and therefore, it facilitates the comparison between countries. The more detailed versions do not allow compatibility between different classification schemes, but they allow the discernment of specific categories that are located at the extremes of advantages or disadvantages in the value of formal education. The position in the occupation also has problems of compatibility with the schemes that are used for some categories. However, in the case of the other categories, such as the top of the social positions or the "employers" or equivalent, it maintains the same definition in all of the examined censuses.

Although it cannot be detailed, it should be mentioned that, like any classification of occupations, those used by the censuses in question also affect the principles and criteria for the definition of categories and groupings. The predominant scheme in the censuses that are used comes from International Standard Classification of Occupations (ISCO) of the International Labour Organization. The classification principles for this scheme are based on a certain type of school meritocracy. This has resulted in an emphasis on the supposed "competence" required for the respective occupation, as well as for the division of labor. Among the effects of this classification scheme should be highlighted the underestimation of resources, such as ownership and control of economic capital, and, depending on the case, the exclusion of categories such as "owners" and "employers", among others of the genre.

As for the other variables under consideration, also for occupation, it is a matter of examining their relations with the value of formal education, both for the countries included and compared with the others. In examining the amount of income and years of study for each category or occupational grouping relative to the average of the whole of the respective universe, what is more important are the differences between these two positions compared to their general average, which is equivalent to the "plus" or to the degree of advantage or disadvantage in the value given to formal education.

Initially, for the most aggregated version, in 10 occupational groupings, in the comparison between the 13 countries, specifically in relation to the position in the respective average of incomes in relation to the total universe, the following stand out in decreasing order: legislators, senior officials and managers, professionals, and, to a lesser extent, technicians and associate professionals. In some cases, the grouping of the armed forces is also positioned at this positive pole of income averages. With few exceptions to a significant degree, these three groups are those whose income averages are higher than the universe of the respective census. Similarly, but far apart, these three groupings are those whose average years of study surpasses that of the set in the universe of the respective census. However, other clusters are included in the above-average situation of the universe regarding years of study, such as clerks, service workers, and shop and market sales for all countries, besides other, which were less expressive.

However, more than the number of clusters located at the positive or negative poles, the differences between the respective positions in the averages of income and years of study are interesting, both for each country taken separately and also in comparative terms. It is a matter of simultaneously considering their positions on the advantages or disadvantages in terms of income and schooling and comparing the "plus" in value given to education. While there is a tendency for occupational groups with the highest average income to also have the highest "plus" in the value of school, there also very significant differences. These differences cover both the clusters of each country considered separately and in the comparison between countries, particularly those from the extreme of the central pole compared to the periphery.

Initially considering the groupings with the highest income average, the legislators, senior officials, and managers, according to country, the highest averages, in a decreasing order, were: Uruguay (4.36 times the average of the total universe), Mexico (4.22), Brazil (3.75), India (3.45), Colombia (3.05), Dominican Republic (2.79), SA (2.55), and Puerto Rico (2.05). To a lesser extent, with less disparity in relation to income averages compared to that of the total census universe, were: Indonesia (1.96), Jamaica (1.74), US (1.69), Canada (1.62), and, finally, Venezuela $(1,52)$. Thus, at this pole of less pronounced differences in income averages for the occupational groupings of legislators, senior officials, and managers are small countries of the periphery, with smaller population and with less differentiated economy, and all countries of the central pole. Taking this same grouping of the legislators, senior officials, and managers and considering the average years of study compared to that of the total universe of each country, the first point that stands out is that there is very little difference, that is, the respective grouping averages, in general, are not much higher to those of the set in the universe of the respective census.

The magnitude of the respective "plus" follows a similar order. On the upper end stands Uruguay, where this occupational grouping has an average income of almost four times that of the years of study (4.36 and 1.07 respectively), which is followed by Mexico, with a lower "plus" (4.22 and 1.75 respectively), Brazil (3.75 and 1.55 respectively), India (3.45 and 1.99 respectively), Colombia (3.05 and 1.50 respectively), Dominican Republic (2.79 and 1.31 respectively), and SA (2.55 and 1.14 respectively). With a lower income and years of study average, and in some cases, with a much lower "plus" were: Puerto Rico (2.05 and 1.10 
respectively), Jamaica (1.74 and 1.09 respectively), US (1.69 and 1.09 respectively), Canada (1.62 and 1.08), and Venezuela (1.52 and 1.08). Therefore, for this occupational grouping of legislators, senior officials and managers, the "plus" of over-value of formal education covers a scope ranging from four times the average of income over that of the years of study to little more than the equivalent, as is the case of Indonesia (1.96 and 1.79 respectively). The central countries have average income of about one and a half times that of the universe of the respective census.

For the grouping of professionals, whose basic criterion of statistical definition is the degree of schooling, although with less intensity, the trends are similar to those found for legislators, senior officials, and managers. In this case, on the upper end of the average income were: Colombia, which also occurs for the years of study (3.23 and 3.0 respectively), followed by Brazil (3.0 and 1.97 respectively), the Dominican Republic (2.34 and 1.23 respectively), Uruguay (2.15 and 1.68 respectively), Mexico (2.10 and 1.84 respectively), and SA (2.05 and 1.19 respectively). With much lower average or "plus" differences were: US (1.43 and 1.27 respectively), Jamaica (1.99 and 1.34 respectively), Puerto Rico (1.66 and 1.23 respectively), Venezuela (2.17 and 1.39 respectively), and Canada (1.31 and 1.19 respectively). The case of professionals even presents a situation where the averages are lower than the years of study in a few Asian countries, such as in India (2.82 and 3.97 respectively) and Indonesia (1.48 and 1.96 respectively).

As for the grouping of technicians and associate professionals, for most countries the superiority of the average income over years of study is minimal, thus approaching neutrality. However, there are strong differences between countries, both in the average of group income and in the "plus" or the differences between averages of income and years of study. In this case, at the extreme of the highest income averages is India, but with a negative "plus", that is, the average income is lower than the years of study ( 2.40 and 2.99 respectively). The same goes for Brazil (1.32 and 2.99 respectively), Colombia (3.12 and 2.30 respectively), and Indonesia (2.50 and 1.84 respectively). The rest of the countries examined have much less significant averages.

For the armed forces grouping, the differences are much more pronounced, with both averages higher than those of the total universe. The same happens when the "plus" in the value is given to education, with some very high and others even negative. For average income of this group, Colombia stands out at the higher end, which includes the difference regarding the years of study (2.92 and 1.45 respectively), which is followtabed by Puerto Rico (2.11 and 1.15 respectively), Jamaica (1.68 and 1.12 respectively), Dominican Republic (1.25 and 1.15 respectively), SA (1.14 and 1.01 respectively), and Mexico (1.33 and 1.14 respectively).

All other occupational clusters in this level of aggregation (10 large groups) other than legislators, senior officials and managers, professionals and, to a lesser extent, the armed forces, are on the negative pole of income averages, except for few cases. This, however, does not occur with the average number of years of study, and these differences result from the aforementioned "plus" over-value of school.

One of the results of assessing the "plus", or degree of advantage in the value of formal education considering the occupational categories at their most disaggregated level and the consequent higher degree of discrimination is increasing the scope of the differences between higher and lower values. The distances between the "plus" of value given to formal education according to central and periphery countries also increases. However, in addition to increasing the scope of differences, the result of examining occupations at this more disaggregated level allows one to consider the composition of those categories that are in extreme positions, higher or lower.

Regarding the scope of extreme differences, as also occurs when occupations are considered according to the 10 groupings, at this more disaggregated level the central countries are distinguished by the lower degree of differentiation between the highest and the lowest position. Regarding the US, considering the classification into 505 categories by the Occupation 1950 basis, in the 1980 census, the occupation at the extreme position with the highest "plus", aircraft pilots and navigators represent 2.47 times the average income advantages over the years of study of the total universe. At the opposite extreme, from the negative plus, are the food counter, fountain, and related occupations, whose index is 0.25 times, like several other categories in the same position. Thus, in this case, the upper end of the positive pole equals less than two and a half times the average of the advantages or "plus" of the total universe, which is far lower than in the case of almost all of the periphery countries. In the case of Canada, this scope of differences is much lower. In the case of disaggregated occupations, with only 25 categories, the National Occupational Classification for Statistics of the 2001 census scheme is used. The one that occupies the uppermost position in the "plus" of senior management occupations has economic advantages or "plus" of 2.15 times the total universe. At the opposite extreme are chefs and cooks, supervisors, and other occupations in the food and beverage service (with a negative "plus" of 0.49 times the total universe).

On the opposite pole in the comparison between countries, the scope of the differences in the advantages or "plus" in the value of education are in the periphery countries, few of which stand out particularly. The countries that stand out regarding differences in the "plus" in value of education, in general, are countries with a larger population and with a

\footnotetext{
2 This "plus" is the result from the division of the average of incomes and years of study for each category by the average of the respective universe. From this result the relative positions of the categories compared to the general averages. However, for the occupations in their more disaggregated level, since what is directly interesting is the scope of differences between the respective positions as to the average of incomes and years of study, the position related to the average of incomes was divided by the years of study. Thus, it is possible to obtain the amount of times one of these positions surpasses the other.
} 
more diverse economy, as already observed when considering occupations according to groupings. One of the periphery countries that occupy an extreme position in this degree of differentiation as to the "plus" in the value of formal education is Brazil, with the upper end category, that of the higher judges, with economic advantage or "plus" of 8.02 times over the years of study when considering occupations with four digits or 510 categories. The category immediately below, of company officers-employers with more than 5 employees- has a "plus" of 5.23 times. At the opposite extreme, of the negative "plus", categories such as heads of small population, with only 0.22 times, lay teachers in elementary education ( 0.30 times), among others.

As for the largest periphery countries examined, the results in Mexico are very similar. The situation in SA is very similar, with the top-level category of directors and chief executives with a "plus" of 4.2 times, followed by legal professionals (with 3.96 times). At the extreme of the negative "plus" are categories such as shoe cleaning and other street service elementary occupations, with only 0.21 times, among others. In turn, the results in Uruguay are like the larger periphery countries, although to a lesser extent.

On the other hand, as in almost all other smaller periphery countries, regarding the scope of the differences related to the "plus" in the value of education, Indonesia represents the lowest among the countries examined. In this case, the toplevel category of accountants has 2.27 times of advantage over years of study. At the opposite extreme are maids and related housekeeping service workers, with only 0.49 times.

Regarding the categories that occupy the extreme positions of positive "plus", although there are many variations, certain common aspects between the countries examined are also evident. In more general terms, occupations in the highest positions in terms of "plus" are usually activities and occupations related to management and imposition of rules, which differs in many of the highest categories. These are not just rules in the formal sense, like the ones in employment contracts, as suggested by the paper [10], and even the ISCO88 classification criteria. Of course, the effects of the labor relations formalities are significant, as evidenced by the strong association between the position of the occupation (class of worker) and particularly the category of employers at the highest "plus" level in the value of formal education. However, when comparing the more disaggregated categories with the position of the occupation (class of worker), it becomes evident that most of those with higher "plus" are formally framed as "salaried workers". These are extremely broad and formal categories, and it seems that the relation between the best situated categories and the "plus", with management and enforcement activities, is due to a sense of possibilities and means of manipulation or their uses based on specific interests. In other words, this is a position and a perspective related not only to social and legal rules, but also to their uses and their fulfillment according to their social position and insertion in the work process. If this is true, it meets what was proposed by the study [7] regarding the differentiated sense of education and its role in recruiting into leading groups. However, this can be taken further, in the sense that it is not only about the importance of "trust" when facing uncertainty during recruitment, but also in the management of occupational activities.

In addition to the categories associated with administration or management, another type of occupation that is very present among those with the highest "plus" in the value of formal education are occupations that consist in the practical application of technical knowledge, usually also having a personal component and organized on the basis of strong regulation and official sanction (which meets what was proposed by the paper [9] and Brown [7]. In quantitative terms, these are particularly occupations of greater prominence in areas such as medicine and the application of legal legislation, and may include, to a lesser extent, the people who teach these occupations. In some cases, some artistic occupations may also be included in this type. To a lesser extent and with a lower "plus", although positive, it also includes several technical occupations, most of which require university degrees.

Another type of category with a high degree of "plus", although much smaller in quantitative terms, but very frequent, is composed of occupations with high technical requirements and generally associated with recent technologies. These are particularly occupations such as aviation pilots and ship drivers, among others. In some specific cases, the high "plus" is not associated with new technologies, but with working conditions such as garbage collectors, dockworkers, and embalmers.

Considering country by country and highlighting a few examples, regarding the US at the top of the "plus", there is a greater prominence of occupations with university degrees in technology, such as physicians, dentists, judges, lawyers, some types of engineers and chemists. However, this does not eliminate the prominence of management-related occupations, such as supervisors, managers, and chiefs. As for Canada, management, business and similar occupations make up almost all of those who rank high on the positive level of the "plus" in the value given to formal education.

Management-related occupations are particularly prominent in periphery countries, especially those associated with public functions. Since the results for these periphery countries are very similar, only a few exemplary cases will be considered. Regarding Brazil, almost all occupations that are at the top of the highest "plus" are linked to the judiciary, public administration, police force, legislative activities, and managers in general, both in the public sector, private sector and similar ones. The main exceptions are physicians, mining engineers, and other occupations involving technology application. In the results are very similar, except for the third position, occupied by ship and aircraft controllers and technicians, and other categories of technicians also at the top. In any case, the first position is occupied by the directors and chief executives, followed by legal professionals and several other categories associated with management, especially in the public sector. Something similar has taken place in Mexico, whose top position is occupied by air 
transportation conductors. Although the results in Uruguay are similar, they have a few peculiarities. As a country with a smaller population and a less diversified economy, there are few occupational categories that have a "plus" in the value of formal education. However, like most other countries, especially the periphery ones, most of the following categories are linked to management, such as legislators, in the second position (with a "plus" of 3.09 times), directors, and chef executives (2.39 times), among other categories linked to management, in addition to those linked to a more intense application of technologies and/or more officially regulated. Other smaller periphery countries further accentuate some of these peculiarities, as is the case of Indonesia, whose top category has a "plus" of only 2.27 times and with a smaller number of categories with positive "plus" in value given to formal education. In summary, despite the lower number of categories with a more significant "plus", the composition does not differ much from the other countries, especially the categories linked to management or the application of technologies with a high level of official regulation. The situation is similar in Jamaica. Finally, considering just one more extreme case of the periphery countries, that of the Dominican Republic, the number of categories with positive "plus" is even lower, that is, only 12 of a total of 27 categories of the classification scheme. The category with the highest "plus" is that of directors and chief executives (2.53 times), followed by general managers (2.02 times), legislators and senior officials (1.85 times), physics, mathematics and engineering sciences professionals (1.85 times), among other categories. In summary, despite the less pronounced differences in comparison to other periphery countries with a larger population and a more diverse economy, the composition of those at the top of the highest "plus" does not show significant differences.

Also, regarding occupational classifications, it is possible to consider the variations in value of formal education according to the position in the occupational status (class of worker). The information regarding this point is somewhat limited, and one of the limitations is how general its definition criteria are. Another limitation is the difficulty in compatibility with the more detailed version, while the use of the more general scheme is too general and therefore not discriminating. Nonetheless, despite the non-systematic compatibility of the set of categories, in this more detailed version, the one that indicates the highest social position of employers is available with the same definition in almost all of the censuses examined.

The results in relation to the value of formal education, particularly for employers, are very significant. The differences between countries and their respective position in the center/periphery relations are also very contrasting. Initially considering the employer category, in the comparison between the countries in question, in the relationship between averages of income and years of study, Brazil stands out at the upper end of the differences (the average income of employers is equivalent to 5.10 of the total universe, and of years of study at only 1.48 times). Right after are: Mexico (3.33 and 1.30 respectively), Colombia (2.67 and 1.16 respectively), SA (2.03 and 1.0 respectively), the US (considered as the category of selfemployed, incorporated, since there is no employer category, with 2.30 and 1.10 respectively), Venezuela (1.92 and 1.03 respectively), Panama (1.93 and 0.90 respectively), and Jamaica (1.59 and 1.0 respectively). To a lesser degree, but also with a general average of income above that of the total universe and with a considerable "plus" are: Uruguay $(1.58$ and 1.12 respectively), the Dominican Republic (1.64 and 1.01 respectively), Puerto Rico (also considering the selfemployed, incorporated category, with 1.76 and 1.01 respectively), and finally, Canada with a much lower "plus" (1.45 and 1.0 respectively). Only India is at the pole where employers had average earnings below that of the total universe, although in this case the category of employers is not available, and the category of self-employed was considered ( 0.82 and 1.08 respectively). In any case, for most countries the status of employer is equivalent to an average income well above the total universe of the respective census, and also, in most cases, a very high "plus" due to the differences with the average of years of study.

In addition to employers who, except in India, in all the countries examined have the highest averages income and the highest "plus" in the value of education, in some cases other categories of employment also have higher income averages than the total of the respective census. However, because this is a more detailed and non-standardized scheme, this other category in a vantage point is very variable, yet it almost always consists of a type of employment with more formal working relationships, public officials, or members of cooperatives. To mention a few examples: for SA, besides the employers, the self-employed are also at the positive pole (1.42 in average income and 0.98 in years of study), in Colombia, the white collar (non-manual) (1.44 and 1.74 respectively), in India the wage-salary workers (1.80 and 2.37 respectively, this is the only case in the positive pole), in Jamaica are the wage-salary workers, government (1.46 and 1.18 respectively), the same occurring in Panama (1.51 and 1.32 respectively), and even more specifically in Puerto Rico with the federal government employees (1.49 and 1.07 respectively), and the US, although to a lesser degree (1.14 and 1.05 respectively for federal government employees), but something similar occurs with the self-employed, unincorporated (1.28 and 1.0 respectively). Lastly, in Uruguay, the members of cooperatives (1.77 and 1.03 respectively) stand out in the same way as they do in Venezuela (1.22 and 0.95 respectively).

The general version with only four categories is more convenient when considering another basic indicator of social position, scholarly titles against averages of income and years of study and the "plus" due to their differences, since it is more standardized. Differently from occupational classifications, the classification schemes of level of schooling are more homogeneous and standardized, which certainly stems from their relationships with the number of 
successful years of study and with the strong formal regulation, since it depends on official sanctions. In all 13 countries examined, the only degree of schooling that is associated with major economic advantages in the value of formal education is having a university degree. For a good part of these countries, people with high school degrees are also positioned at the positive pole, with some advantages in average incomes above that of the total universe. However, in addition to the strong variation among countries in income averages relative to the degree of schooling, the "plus" obtained in the value of schooling is also very diverse. In other words, for some countries this degree of schooling equals a very high average income, but in some cases this average income is not much higher than that of years of study, therefore with a reduced "plus", contrary to what happens in other countries, particularly regarding people with university degrees. Initially considering the countries that stand out for the highest income averages depending on higher schooling degrees or university degree, Colombia is in the extreme. In this case, the average of those with this degree exceeds almost six times (5.63) that of the total universe. However, in this case the "plus" of the over-value of education is not very high, since those with a higher education degree have an average of years of study of more than five times (5.09) than the total universe. In the second position regarding average of income for people with higher education degrees is SA, with more than five times (5.54) the average of the total universe, implying a very high "plus", since the average of years of study of people with this degree does not reach twice (1.74) that of the total universe. Several other countries approach SA in varying degrees, such as Brazil (4.07 and 2.85 respectively), Jamaica (3.32 and 1.83 respectively), and Puerto Rico (4.07 and 2.57 respectively). Another set of countries presents very small differences in the relationship between average incomes and years of study of people with higher education degrees, generally those with a smaller population and with a less diverse economy, besides those of the central pole, such as Canada and the US. Among these small countries with the lowest difference between average income and years of study are the Dominican Republic (2.82 and 2.93 respectively), Uruguay (2.48 and 2.33 respectively), and Venezuela (2.37 and 2.25 respectively). As for the central countries, this difference between the average income and years of study for university graduates is almost non-existent, as in the cases of Canada (1.49 and 1.36 respectively) and the US (1.73 and 1.69 respectively).

On the other hand, there are some exceptions or very particular situations with a negative "plus" among the periphery countries, since the average income is lower than the years of study for those with a university degree. In general, the countries which present an exceptional situation in relation to others in level of schooling are also in a specific situation regarding other indicators. In the case of schooling, this is particularly true in the case of India, with an average income much lower than the years of study, that is, with a negative "plus" for those with a degree in higher education
(3.44 and 6.32 respectively), and to a lesser extent, Indonesia ( 2.60 and 2.88 respectively). With regards to the relatively advantageous position of those with the equivalent of a high school degree, this applies particularly to countries such as SA (1.94 and 1.61 respectively), Brazil (1.43 and 2.08 respectively, with negative "plus"), Colombia (2.33 and 3.68 respectively), with an average income above the total universe, but lower than that of the study years, India (2.33 and 4.73 respectively, likewise), Indonesia (1.38 and 2.23 respectively, likewise), the Dominican Republic (1.41 and 2.23 respectively, likewise), Uruguay (1.17 and 1.68 respectively, likewise), and Venezuela (1.47 and 1.53 respectively). Therefore, although most periphery countries with the equivalent of a high school degree have an average income somewhat higher than that of the total respective universe, for the most part they have a negative "plus", with average years of study higher than that of income. For the rest, the economic advantage in comparing income averages and years of study is relatively restricted.

In addition to the more direct social position indicators, like income, occupational classifications, and school titles, the sources presented a series of indications that consist of what are generally classified as "demographic" variables. For this article, it is important to point out that these are more direct or indirect indications of resources for social integration and insertion particularly associated with cultural capital and with the cleavages and identity positions based on different principles. Since they are resources associated with conditions for social integration and center/periphery relations, they can constitute conditions of recognition and, thus, of social capital [4]. In general, these are indicators with strong associations with the differentiated value of formal education. However, as already mentioned, since presenting these results would be too extensive in this text, they will be presented in another article which concentrates on social capital.

\section{Conclusion}

As stated at the beginning, it is the presentation of a partial result of a study whose research object is the differentiated value of formal education as a result of confrontations between resources and principles of social hierarchy. Formulated this way, issues related to the supposed value of education are not directly included in the study object, either in terms of the "return" of economic investments or their "social" effects. However, although not directly included, this type of issue constitutes an obstacle to the analysis of what is at stake, that is, the social conditions of the differentiated value of formal education. The moral value of what is attributed to "education" is present as a pre-constituted problem not only in political-ideological confrontation, but also in most of the relevant literature.

However, regardless of the problems arising from the prior constitution of problems related to the value of education, one of the main problems and thematic axis is the relationship between what is socially intended and 
categorized and what is implicit or tacit in the principles of social hierarchy and practices. According to the general hypothesis, the differentiated value of formal education is directly associated with the relationship between what is intended and categorized, in this case, particularly through school titles in relation to different markets, and what is implicit in the principles of social hierarchy and practices. It is in this axis of analytical problems that the relationships between social categorizations and statistical classification schemes and their methodological implications become important. Also, in this axis of analytical problems questions of hierarchies based on commonly-used social position indicators are central, along with those associated with the center/periphery relationship, and what is generally attributed to social capital. It shows that, particularly regarding social capital, like the questions related to "education", if, on the one hand, a sociological problem is on the agenda, on the other, there is also the constitution and foundation of mythologies based on the civic morality in force. This paper has focused on the first of these axes, the one more directly focused on the relationships between the differentiated value given to formal education and the social position indicators, and the rest will be presented in another article.

This study has presented good evidence to confirm the hypothesis that was originally posed. The results for the relationship between differentiated valuation of formal education and the available indicators of social position are very forceful and systematic. This applies both to the internal examination of each country considered and to the comparison between countries. On the other hand, there are also many questions whose empirical demonstration, despite advances, still lacks further specification and detailed examination. This applies particularly to questions involving classification schemes and statistical categorizations, such as those relating to what can be considered as social capital or to the set of less socially intended hierarchical principles. However, like all works of sociological research, rather than definitive answers, what is important are the advances and possibilities for formulating new research questions.

\section{References}

[1] Badie, B (1994). Le modèle centre-périphérie. In. Badie, (ed.). Le Développement Politique. Paris: Economica, 111-133.
[2] Baudelot et al. (2004). Les Effets de l'Éducation; Rapport à l'Intention du Piref. Paris: Ecole Normale Supérieure.

[3] Bourdieu, P (1980). Le Sens Pratique. Paris: Les Éditions de Minuit. [The Practical Sense. Paris, The Editions of Minuit].

[4] Bourdieu, P (1980b). "Le capital social." Actes de la Recherche en Sciences Sociales 31 (1): 2-3.

[5] Bourdieu, P (1984). Homo Academicus. Paris: Les Éditions de Minuit.

[6] Bourdieu, P (1989). La Noblesse d'État; Grandes Écoles et Esprit de Corps. Paris: Les Éditions de Minuit.

[7] Brown, D K (2001). The social sources of educational credentialism: status Cultures, labor markets, and organizations. Sociology of Education 74: 19-34.

[8] Coleman, J S (1988) Social capital in the creation of human capital The American Journal of Sociology Supplement: Organizations and Institutions: Sociological and Economic Approaches to the Analysis of Social Structure 94: S95-S120.

[9] Collins, R (1979). The Credential society: an historical sociology of education and stratification. Cambridge: Academic Press.

[10] Erikson R, Goldthorpe J H, and Portocarero L., (1983). Intergenerational Social Mobility and the Convergence Thesis. British Journal of Sociology 34 (3): 303-343.

[11] http://www.encup.gob.mx/en/Encup/(Avaiable at 12/08/2017).

[12] https://international.ipums.org/international/Minnesota Population Center. (2015). Integrated Public Use Microdata Series, Minneapolis: University of Minnesota (Avaiable at 12/08/2015).

[13] Lin, N, Cook, K, and Burt, R S (2008). Social Capital; Theory and Research. (eds.). Brunswick: Aldine Transaction.

[14] Putnam, R D (1992). Making Democracy Work; Civic Traditions in Modern Italy. Princeton: Princeton University Press.

[15] Putnam, R D (2000). Bowling Alone; The Collapse and Revival of American Communit. New York: Simon \& Schuster.

[16] Weber, M (1984). Economia y Sociedade; Esbozo de Sociología Comprensiva. México: Fondo de Cultura Económica.

[17] Weber, M (2002). The Protestant Ethic and the Spirit of Capitalism. London: Routledge.

[18] www.worldvaluessurvey.org (Avaiable at 03/04/2015). 